\title{
INTEGRATING MAGNETIC AND GPR SURVEY AT ÇATALHÖYÜK
}

\author{
K. Strutt ${ }^{1}$, S. Campana ${ }^{2}$, J. Ogden ${ }^{3}$, G. Catanzariti ${ }^{4}$, G. Morelli ${ }^{4}$ \\ 1 University of Southampton (UK), Archaeological Prospection Services of Southampton; K.D.Strutt@ soton.ac.uk \\ 2 University of Siena (Italy), Ancient Topography, Laboratory of Landscape archaeology and remote sensing; campana@unisi.it \\ 3 University of Southampton (UK), Web Science Institute; j.ogden@lparchaeology.com \\ 4 Geostudi Astier srl Livrono (Italy); gianluca.catanzariti@gmail.com; gf.morelli@ tin.it
}

\section{Introduction}

As part of the 2010 and 2012 field seasons at the site of Çatalhöyük, geophysical survey was conducted with the aim of mapping parts of the sub-surface remains at the site. While extensive excavations have been conducted on the East Mound, a considerable part of the area of this mound is still largely unknown in terms of the presence of archaeological deposits and possible Neolithic structures. Previous magnetometry conducted over the central part of the East Mound in 1992 and 1993 (Shell 1996) provided some shallow sub-surface data for the nature of the archaeology, although the results were not entirely conclusive. Further geophysical survey was also conducted in 2000 by Johnson and Dobbs, using magnetometry, ground penetrating radar (GPR) and electrical resistivity tomography (ERT) (http://www.archaeology-geophysics.com/Catalhoyuk.html). No other geophysical survey has been carried out at the site, and thus the potential for assessing the extent and form of structural remains at Çatalhöyük is considerable. To this end two seasons of geophysical survey were conducted at Çatalhöyük: in 2010 by a team from the University of Southampton, and in 2012 by a joint British and Italian team from the University of Southampton (UK), the University of Siena (Italy) and the company Geostudi Astier (Italy). Work focused on the area of the East Mound around the North Shelter and the central part of the mound to the east of the South Shelter (Fig. 1). In addition, an area of survey was conducted to the south of the West Mound, to test the survey methodology and assess the potential for evidence of deposits associated with the main Neolithic settlement.

\section{Research Objectives}

The primary objective of the geophysical survey was to map a significant proportion of the East Mound at high resolution using magnetometry and ground penetrating radar (GPR), to provide data for the mapping of sub-surface structures. Bearing in mind the stratigraphic information from the excavations, the results of the geophysical surveys would facilitate the creation of an extended plan of the settlement.

The second objective was to establish a correlation in the data with the materials present across the site. The inhabitants of Çatalhöyük lived in mud-brick houses that were constructed in a closefitting network of walls and living spaces. From the results of the excavations it is hypothesised that there were no footpaths or streets between the dwellings - most living spaces were accessed by holes in the ceiling (Hodder 2006). These structures were at times levelled and infilled with debris, and new structures were then constructed on the levelled areas. The form of construction and the nature of the surrounding soil matrix suggests a very low contrast between the natural background and the remains of past structures, which could be basically defined as clay on clay. Considering the number of archaeological sites with similar fabric, consisting mainly of mud brick and wall plaster, the application of these techniques adds to the corpus of comparative data for mud-brick sites across the Mediterranean, North Africa, and the Levant. 
Our survey used magnetometry and ground penetrating radar (GPR) techniques to map the subsoil, with real-time kinetic (RTK) GPS to establish the survey grids and measure the topography (Fig. 2). The geophysical methods utilise different sensors to measure different physical properties of the soil. In the case of magnetometry we used a fluxgate gradiometer to carry out the survey, a system that utilises two sensors at opposite ends of a vertical tube (Clark 1996, 69) to measure variations in the local magnetic field in nanotesla (nT). These changes occur due to the presence of materials with either permanent or remnant magnetic properties, or with a magnetic susceptibility in the presence of the Earth's magnetic field. Buried materials that can cause variations include burnt soils, kilns, hearths, and structural remains such as walls. Thus, the varied deposits at Çatalhöyük, taking the form of mudbrick walls, areas of levelled deposits, potential hearths and other deposits, can be mapped using the technique. The method of GPR utilises a system where a radar wave is propagated into the ground, measured in megahertz (MHz), and reflection traces are recorded (Conyers 2013, 29). Reflection from buried deposits and structures can then be mapped, with contrasts in the materials showing in the GPR profiles, and amplitude slices allowing images of buried features to be created for different depths through the deposits.

These methods carry a number of caveats; the depth of the tell deposits at Çatalhöyük extend for over $18 \mathrm{~m}$ below the modern ground surface, with the magnetometry realistically providing data for the upper $1.5 \mathrm{~m}$ of deposits, and the GPR survey providing data to a depth of around $3 \mathrm{~m}$ (Aspinall et al 2009; Conyers 2013). While the Neolithic deposits at Çatalhöyük commence at a relatively shallow level (Hodder 2014) with no extensive later deposits on the mound, the results of the survey do not provide evidence for the deeper stratigraphy of the mound. Deeper layers could be surveyed in the future using methods such as electrical resistivity tomography (ERT) where measurements of the resistance to the passing of an electrical current to increased depths can be used to map variations in deposits (Schmidt 2013). However, such techniques also have their own limits on the survey extent and resolution of data.

While no large scale extensive structures are present on the mound for the historical period, a number of more ephemeral features ascribed to the Byzantine and Ottoman periods were present on the mound, including burials and the presence of drying or threshing platforms, used for the drying and threshing of grain in the Ottoman and modern periods, visible in the air photographic record for the $20^{\text {th }}$ century. As a result interpretation of the magnetometry and the shallower reflections from the GPR survey need to take into account the possible presence of later deposits on the East Mound, and the survey in the environs of Çatalhöyük need to take into account deposits formed through natural and agricultural practices in the floodplain.

\section{The Survey Methodology}

The magnetometer survey was conducted using a Bartington Instruments Grad601-2 dual sensor fluxgate gradiometer. Data were collected along traverses spaced $0.5 \mathrm{~m}$ apart at $0.25 \mathrm{~m}$ intervals. The magnetometer survey data were imported into and processed using Geoplot 3.0 software.

The single antenna GPR survey of 2010 was conducted using a Sensors and Software instrument with Smart Cart, and a $500 \mathrm{MHz}$ antenna. Traverses were surveyed in zig-zag fashion at $0.5 \mathrm{~m}$ intervals across the survey area, with trace measurements taken at $0.025 \mathrm{~m}$ intervals. The Subsurface Tomographic Radar Equipment for Assets Mapping (STREAM) was used in the 2012 season. This is a multiple antenna radar system. The module is designed for large-scale archaeological prospection and comprises a vehicle-towed trolley that pulls a $1.68 \mathrm{~m}$ wide GPR massive array working at $200 \mathrm{MHz}$, containing 16 dipoles with parallel orientation and a spacing of $0.12 \mathrm{~m}$ (Novo et al 2013). The data acquisition at Çatalhöyük was carried out by mounting the array behind a tractor vehicle. The unavailability of a quad vehicle forced the team to modify the equipment for a Kubota tractor, introducing some limitation in the stability and the efficiency of the data collection system. The survey area of 3.4 ha was covered over 3 days of fieldwork. All GPR data from both single antenna and STREAM X systems were processed using GPR Slice software. 
In addition to the geophysical survey, a topographic survey was also conducted of the East Mound and the survey area to the south of the West Mound, to provide a backdrop to the geophysics.

\section{The Survey Results}

The Topography - The 2012 topographic survey was conducted in the area to the south-west of Çatalhöyük. The topographic survey off mound (Fig.3, right) indicated a number of interesting features that relate to the geophysical survey results. First, the entire central and western part of the survey is covered with a rippling effect, with each band measuring 11-12m across, suggesting the effect on the modern plough soil through strong winds. The fall and slight rise in the topographic data in the eastern side of the fields, originally thought to relate to a palaeo-channel and geoarchaeological features, seems to be formed entirely from later agricultural activity, with the rise matching the line of a field boundary visible in the 1940s air photography. This is a significant aspect of the landscape, as many of the features visible on the modern ground surface may not actually relate to prehistoric or Byzantine archaeology, but to more recent aspects of agriculture and soil formation.

The East Mound - Approximately 7.5 hectares of magnetometry were conducted at Çatalhöyük on the East Mound (Fig.4). A number of strong dipolar responses [m1.1], [m1.2], [m1.3], [m1.4], [m1.5] and [m1.6] alongside the southern and eastern edge of the North Shelter (Fig.5) mark remnants of iron rebar and other ferrous material associated with excavation at the site. However, a large number of anomalies appear in the magnetometry in the northern sector of the East Mound, indicating the remains of structures across the mound. Immediately to the west of the North Shelter three adjacent structures are indicated by a series of linear and curvilinear features [m1.7], [m1.8] and [m1.9]; (A).

A rectilinear area of walls $[\mathbf{m 1 . 1 0}],[\mathbf{m 1 . 1 1}]$ and $[\mathbf{m 1 . 1 2}]$ to the north of the North Shelter marks a further area of structures (B). A continuation of possible structural remains is visible to the northeast of the shelter $(\mathbf{C})$, although the responses in the data are more fragmented. A linear positive anomaly [m1.15] and [m1.16] suggest the line of a wall. A series of discrete positive [m1.18] and linear [m1.19] responses to the east suggest a continuation of building remains in this area of the mound.

A return of these features [m1.20], showing negative deposits and a possible positive wall, runs from north to south. Linear positive responses to the north-east of the excavations [m1.23] also indicate the presence of structures further down the flanks of the mound, although some modern disturbance [m1.24] is also visible.

The area to the south-east of the North Shelter does not show any strong linear features in the magnetometry. Several positive discrete responses, [m1.25] and [m1.26], on linear alignments spreading west to east, suggest possible midden or dumped deposits. A negative and positive linear anomaly [m1.29] and [m1.30] runs from west to east across the site, again indicating the presence of a buried wall. Dipolar linear [m1.31] and several positive linear features [m1.32] and [m1.33] extend westward from the edge of the North Shelter, for a distance of 15-16m, indicating the presence of structures to the west of the excavations (D).

A positive rectilinear response [m1.34] measuring $10 \mathrm{~m}$ by $7 \mathrm{~m}$ indicates a structure to the west, and two positive rectilinear anomalies [m1.35], adjacent to one another also suggests similar structural remains (E). A number of linear and rectilinear positive features [m1.36] and [m1.37] close to the excavation house, suggesting possible structures, some $9 \mathrm{~m}$ by $6 \mathrm{~m}$ in size. These features seem to continue to the north [m1.38], and some fainter disturbance is visible to the east [m1.39].

On the eastern flanks of the mound a negative linear anomaly [m1.46] runs from north to south, marking a field boundary ditch. A second ditch and bank [m1.47] crosses the mound from west to east running off the eastern flank of the mound [m1.48] covering a distance of $126 \mathrm{~m}$. Several ovate and sub-circular anomalies are visible along the edge of the survey area [m1.49] and [m1.50], [m1.51] and [m1.52] marking possible threshing floors associated with agriculture. To the south several discrete positive and negative responses [m1.55] and [m1.56] mark possible modern burials on the 
flank of the mound, however others [m1.57] and [m1.58] are especially obvious further to the east. A number of positive linear and discrete anomalies [m1.60], [m1.61] and [m1.62] mark faint traces of structural remains on the eastern side of the mound $(\mathbf{F})$.

On the principal heights of the East Mound, to the east of the South Shelter, a strong pattern of linear and discrete features marks a concentration of settlement in the area. Two strong linear responses [m1.67] and [m1.68] are visible, with a large open area [m1.69] measuring $25 \mathrm{~m}$ by $10 \mathrm{~m}$, marked with discrete responses suggestive of fired material. To the south a second large rectilinear anomaly [m1.70] measuring $25 \mathrm{~m}$ by $10 \mathrm{~m}$ and a series of linear positive anomalies [m1.71] are visible. A series of smaller linear and rectilinear anomalies are located to the south [m1.72], [m1.73] and [m1.74] indicate houses (G).

Three sets of linear positive features [m1.75], [m1.76] and [m1.77], the first running from north to south, and the second two from west to east, mark a building measuring some $13 \mathrm{~m}$ by $10 \mathrm{~m}$ in size. To the east, and on the flank of the mound a set of positive magnetic responses [m1.79] and [m1.80] run from south-west to north-east, suggesting a change of alignment in the structures along this side of the mound. To the south and west of the high ground a large number of linear and rectilinear features [g1.81], [m1.82], [m1.83] and [m1.84] show buildings $(\mathbf{H})$ extending down the side of the mound in a north to south orientation.

A series of positive linear magnetic responses [m1.85], [m1.86], [m1.87] and [m1.88] extend from west to east across the highest point of the East Mound, showing the presence of buildings (I). The pattern of linear anomalies extends along the western and north western side of the mound [m1.98] [m1.101]. A series of discrete positive and dipolar responses [m1.104] and [m1.105] on the side of the mound show the presence of structures or middens. In the southernmost area of the magnetometer survey, several linear and discrete features [m1.109] and [m1.110] mark the presence of buildings and midden deposits.

The single antenna GPR survey conducted in 2010 and 2012 (Fig. 6) revealed a number of features immediately to the north of the North Shelter and on the flanks of the mound. A single strong high amplitude linear response [G1] and [G2] runs from west to east close to the shelter for a distance of $28 \mathrm{~m}$ with a short break in it, suggesting the line of a wall associated with a series of buildings. Two rectilinear anomalies [G3] measuring some $4 \mathrm{~m}$ by $6 \mathrm{~m}$ indicate the presence of two adjacent buildings to the east. A second linear high amplitude anomaly [G4] and runs for a distance of $30 \mathrm{~m}$, from west to east, forming one side of a rectilinear anomaly [G5] showing a further building.

A series of three short linear features [G9] and [G10] indicate buildings measuring some $7 \mathrm{~m}$ across. Two smaller buildings are visible [G11] and [G12] immediately to the east, with a complex of rooms or buildings [G13], [G14] and [G15] to the east and south, measuring in total some $18 \mathrm{~m}$ by $12 \mathrm{~m}$. The structures run to the eastern edge of the survey area [G16] and [G17].

A set of linear anomalies [G18] running from north to south for a distance of $15 \mathrm{~m}$, mark the western side of a possible large open area [G19] measuring some $14 \mathrm{~m}$ by $9 \mathrm{~m}$. A second open area [G20] is located immediately to the north. The high amplitude linear anomalies continue to the north and east [G21], [G22], [G23] and [G24] showing the extension of structures onto the flanks of the mound. Further to the north, the double linear anomaly located in the vicinity of the shelter continues to run for a further 55m to the north [G25], with evidence of linear anomalies to the north and west [G26] suggesting further structural remains.

With the STREAM X data three levels of data are represented, with the shallowest level presented here. In the shallowest level $(0.3-0.5 \mathrm{~m})$ for the north of the East Mound (Fig. 7) a double linear high amplitude feature [SN1.1] and [SN1.2] measuring 18m in length marks the sides of structures and a possible trackway or route between them. To the east of these two linear high amplitude responses mark structural remains [SN1.3], whereas a set of curvilinear low amplitude features [SN1.4] mark the remains of modern threshing floors. A series of linear and rectilinear anomalies on the north east side of the mound [SN1.5] indicates buildings, with a series of similar responses [SN1.6], [SN1.7], [SN1.8] and [SN1.9] seem to indicate buildings and a strong edge to the structures located at the base of the steeper topography along the eastern side of the mound. Similar responses are located on the 
flanks of the mound to the east [SN1.17], [SN1.18] and [SN1.19] showing buildings measuring between $7 \mathrm{~m}$ and 10m across. Several low amplitude responses [SN1.20] indicate further threshing floors, with high amplitude linear anomalies [SN1.21] and [SN1.22] showing structures farther to the south.

To the north-west of the shelter a series of high amplitude features [SN1.23] and [SN1.24] extend westward [SN1.25]. Two parallel and large linear low amplitude anomalies [SN1.26] and [SN1.27] run for a distance of over $32 \mathrm{~m}$, marking possible track-ways or routes between buildings. Along the western side of the shelter a series of linear responses [SN1.28] - [SN1.31] mark buildings extending from the excavations under the shelter. A number of fainter high amplitude anomalies are located to the east (Fig. 8) [SS1.20], [SS1.21], [SS1.22] and [SS1.23]; however it is difficult to see any coherence or articulation in the form of the features. In the south eastern portion of the survey area several linear and rectilinear anomalies [SS1.24] - [SS1.29] do suggest the continuation of the walls of structures.

The South Excavations and Buildings 80 and 89 - The more focused GPR surveys of the area immediately to the east of the southern shelter, and of buildings 80 and 89 (Fig. 9) within the southern excavation area, indicate a number of features. To the east of the shelter both single antenna and STREAM X surveys indicate a continuation of the walls and buildings found in the excavation (structures A and B), and the presence of a number of possible tombs (discrete features $\mathrm{C}$ and D). Results of the GPR survey from buildings 80 and 89 also show the presence of burials in the northeastern corner of each building, and the presence of room furniture at a depth of $0.5-1.5 \mathrm{~m}$. Deeper deposits indicate the presence of other deposits and features, probably associated with earlier rooms and buildings, also indicating the presence of deeper burials and pits.

Work beyond the East Mound focused on the locating of possible palaeo-channels to the south and south-west of Çatalhöyük. A topographic survey conducted with the GPS in this area indicated a rise in the topography which, together with the results of the magnetometry (Fig.5), shows the location of a possible channel on the higher ground in the eastern part of a modern arable field, running from south to north towards the lower ground to the south of the West Mound.

\section{Discussion of results}

The results of the combined geophysical survey at Çatalhöyük have facilitated the mapping of many of the buried structures and features at the site (Fig. 10). While many linear and curvilinear features can be associated with the modern agriculture and use of the mound for farming activity, and some of the positive discrete anomalies on the eastern flank of the mound can be ascribed to later burials, a large number of anomalies in the magnetometry, and particularly in the GPR survey results show Neolithic structural remains.

On the northern part of the mound the settlement can be seen extending northwards down the flank of the mound (C). The settlement concentration also runs to the west (E) and south (D), although the break in slope and the small valley in the topography seem to indicate either a break or a reduction in structures. At least one if not two track-ways with enclosing walls are indicated running into the settlement from the north. Two parallel linear anomalies running to the west also seem to indicate a track-way running from the northern part of the settlement downslope to the west.

Results of the survey in the southern part of the mound are in some cases less clear. The magnetomery indicates a number of structures and walls $(\mathbf{G})$ and $(\mathbf{H})$; however there is more disturbance in the results for this area. The STREAM X data shows some west-east alignment of walls and buildings; however the data were collected in a west-east series of traverses and as a result some of the features are difficult to trace. A change in orientation seems to occur along the higher flank of this area (I), suggesting a strong line of structures, with fewer linear features to the east and south, showing some settlement but nothing of the scale of concentration of settlement as can be seen on the main mound. 
The survey to the east of the South Shelter indicates the continuation of structures beyond the shelter, with a strong wall feature and a series of possible burials. Similarly the single antenna surveys in the southern excavations indicates room furniture and burials in buildings 80 and 89 . On the basis of the integrated geophysical survey results for the East Mound at Çatalhöyük, and the extent of anomalies represented in the data, there are a number of locations where results of the geophysics could be 'ground-truthed', using targeted trial trench excavation over specific features, to test the results of the survey. This would enable investigation of anomalies and features present in the geophysical survey data and would allow the edges of the known settlement at Çatalhöyük to be assessed, together with the varying nature of some of the structural deposits.

The complex nature of the survey results from the East Mound also must be acknowledged. This paper presents a summary of the findings in both datasets. However, the complexity of the deposits at Çatalhöyük and the number of responses in the magnetometer and GPR datasets means that further analysis and interpretation of the data ought to be carried out, focusing on key areas of the site, for instance in the area surrounding the North Shelter.

In addition, there is still scope to complete the magnetometer and GPR surveys of the East Mound, and the possibility of extending the survey to the West Mound also. Both GPR and magnetometry seem to respond well to the type of deposits present at Çatalhöyük, although not all features show clearly in each set of results when taken individually. It is therefore recommended that any future survey incorporates both methods as a means of optimising the interpretation of the survey results.

On the basis of the results of the topographic and magnetometer survey conducted off the mound, it would appear that the use of an integrated survey methodology would enhance the study of the environs of Çatalhöyük, particularly in relation to the study of the geomorphology and the location of archaeological deposits and settlements associated with the changing environment. This would be most suitable as a component of a larger geo-archaeological study of the landscape surrounding Çatalhöyük.

\section{Acknowledgements}

The authors would like to thank Prof. Ian Hodder for inviting the survey teams to conduct research at Çatalhöyük in the 2010 and 2012 seasons. The advice and help of Shahina Farid and Banu Aydinoglugil is gratefully acknowledged. Finally, we extend a warm thank you to the survey team, Samantha Bax, Grant Cox, Eleanora Gandolfi and Meya Kellala, who were pivotal in ensuring two successful seasons of survey.

\section{References}

ASPINALL A., C. GAFFNEY \& A. SCHMIDT 2009. Magnetometry for Archaeologists. Plymouth-UK: AltaMira Press.

CLARK, A. 1996. Seeing Beneath the Soil. Prospecting Methods in Archaeology. London. Batsford.

CONYERS L.B. 2013. Ground-Penetrating Radar for Archaeology. Plymouth-UK: AltaMira Press.

HODDER I. 2006. Çatalhöyük. The Leopard's tale. London: Thames \& Hudson.

HODDER I. (ed.) 2014. Çatalhöyük excavations: the 2000-2008 seasons. Çatalhöyük Reseach Project Series Volume 7. British Institute at Ankara Monograph No. 46/ Monumenta Archaeologica 29. Los Angeles: Cotsen Institute of Archaeology Press.

NOVO A., J. LECKEBUSCH, D. GOODMAN, G. MORELLI, S. PIRO \& G. CATANZARITI. 2013. Advances in GPR imaging with multi-channel radar system. Journal of Surveying and Mapping Engineering 1 (1): 7-14.

SCHMIDT A. 2013. Earth Resistance for Archaeologists. Plymouth-UK: AltaMira Press.

SHELL, C. A., 1996. Magnetometric Survey at Çatalhöyük East. In Hodder, I. (Ed.), On the Surface: Çatalhöyük 1993-1995, Cambridge: 101-113. 